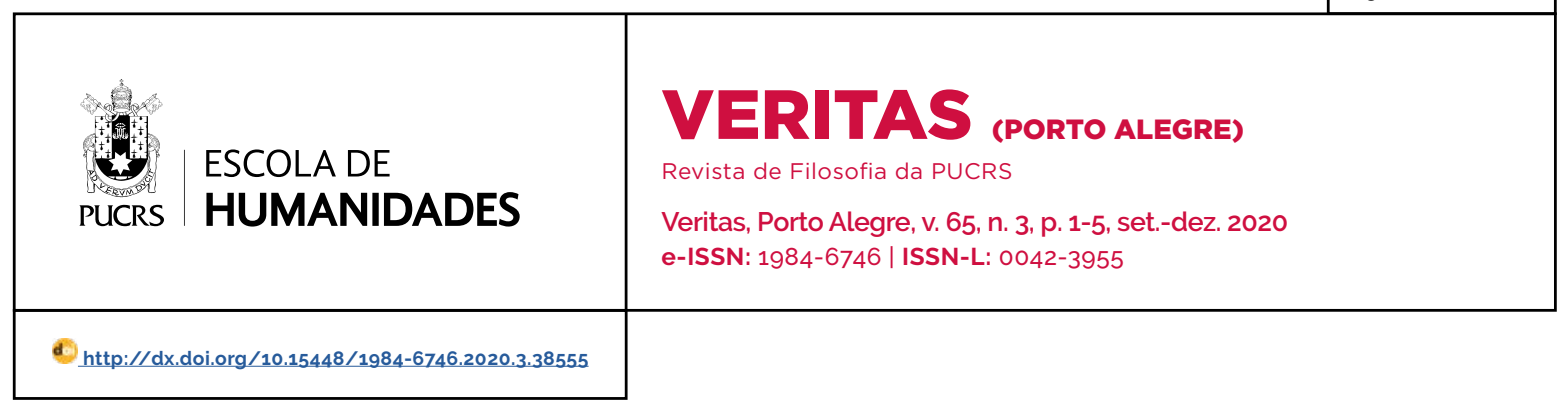

SEÇÃO: RESENHA

\title{
"Marx selvagem"?
}

"Wild Marx"?

¿»Marx salvaje»?

\section{Marcos de Almeida Matos $^{1}$}

orcid.org/0000-0003-0546-9345 tapecuim@gmail.com

Recebido em: 12/7/2020. Aprovado em: 12/11/2020. Publicado em: 12/01/2021.

\section{(c) (i)}

Artigo está licenciado sob forma de uma licença Creative Commons Atribuição 4.0 Internacional.
TIBLE, Jean. Marx Selvagem. 4. ed. São Paulo: Autonomia Literária, 2020.

Originalmente uma tese defendida junto ao Programa de Pós-graduação em Sociologia da Universidade Estadual de Campinas, em 2012, o livro Marx Selvagem (quarta edição, São Paulo: Autonomia Literária, 2020) preserva o estilo de uma tese acadêmica, tanto pela ordenação da exposição quanto pelo grande número de citações. Segundo o autor, o objetivo do livro é o de ressaltar o "encontro entre Karl Marx e a América Indígena".

Na prática, trata-se, inicialmente, de recuperar a démarche do pensamento marxiano a partir da leitura que o pensador alemão fez de Lewis Henry Morgan e dos estudos sobre as formas comunais de propriedade atribuidas à comuna rural russa (MIR). Em um segundo momento, tem-se a aproximação entre os argumentos de Marx sobre a natureza das sociedades sem classes e a abolição do Estado, e as análises do antropólogo gascão Pierre Clastres, autor da conhecida tese sobre as "sociedades contra o Estado". Por fim, Tible procura aproximar a imagem resultante de Marx das intervenções escritas em coautoria por Davi Kopenawa e Bruce Albert, bem como das análises etnológicas que ganharam notoriedade sob a rubrica de "perspectivismo ameríndio", especialmente, através da obra do antropólogo Eduardo Viveiros de Castro.

O livro é composto de três capítulos, precedidos por uma introdução, "Marx e América Indigena". Nessa, Tible declara a intenção de aproximar Marx da América Indígena, com o propósito explícito de relançar a dimensão universal tradicionalmente almejada pelo marxismo internacionalista, que deveria então ser pensada como "o comum": aquilo que resulta da "conexão das múltiplas lutas" (2020, p. 28). Enfatizando a ligação postulada por Marx entre a teoria e a práxis revolucionária, Tible declara como ponto de partida para o seu estudo a obra de José Carlos Mariátegui, fundador do Partido Comunista do Peru e autor do clássico 7 Ensaios de Interpretação da Realidade Peruana (publicado pela primeira vez em 1928).

O primeiro capítulo, "Marx, Engels e os 'outros': uma leitura dos seus escritos que vão além da Europa Ocidental", é um relato sobre as leitu- 
ras e as análises de Marx acerca das formações sociais "não" ou "pré-capitalistas". Noves fora, o capitulo se resume às referências de Marx à Morgan (principalmente o da Ancient Society, de 1877) e aos estudos sobre a comuna rural russa. Aqui o ponto de Tible é provar que Marx abandonou cedo a ideia de que o progresso ou o desenvolvimento levaria à extinção as formações sociais pré-capitalistas, ao contrário de Engels (que manteve sempre um "determinismo trágico unilinear", segundo Dussel). Tible procura mostrar como Marx atentou cada vez mais para a ligação entre o colonialismo e o capitalismo, vendo na colonização um exemplo privilegiado da natureza da "acumulação originária" (que Marx teria chamado de "expropriação original", em 1865). Marx, ao ler Morgan, teria prestado atenção nas formas de organização política sem Estado (a "Liga dos Iroqueses", por exemplo) e na relação entre diversos regimes de propriedade fundiária (a distinção societas e civitas, a passagem de uma à outra etc.). Dai surge a imagem de um "comunismo primitivo", baseado na propriedade comunal da terra. Essa imagem poderia ser projetada como o sentido da emancipação dos trabalhadores, e, para Tible, Marx toma a propriedade comunal como, digamos, não marcada, e a separação dos trabalhadores de seus meios de produção como o que deveria ser explicado. Tible usa essa mudança de perspectiva para falar que há uma "revolução copernicana" em Marx, análoga àquela sugerida por Clastres no artigo Copérnico e os selvagens. Por fim, Tible sugere que essa imagem do "comunismo primitivo" foi também evocada pelos artífices de outras utopias comunistas, como Rosa Luxemburgo, Lenin, Mariátegui e até Walter Benjamin. O capítulo é concluido com a tese de que Marx recorre às "sociedades sem classe" não apenas para explicar as origens do capitalismo, mas para "investigar novas possiveis forças revolucionárias" (2020, p. 108).

No segundo capitulo, «Marx e Clastres contra o Estado", o autor busca aproximar Marx e Clastres partindo das leituras que veem em Marx um pensamento político em sentido forte, contra a determinação do político pelo econômico, como na vulgata marxista. Marx teria buscado se contrapor à visão hegeliana do Estado, principalmente expressa nos Princípios da Filosofia do Direito, que naturalizava o Estado como unidade final dos interesses particulares e do universal. O Estado hegeliano pretendia-se o grande uno, representado pela soberania do rei e cuja consciência seria a burocracia. Contra isto, Marx coloca em cena uma dicotomia: ou a soberania do monarca ou a do povo. Marx teria, segundo Tible, passado por uma fase "democrática", que via na democracia conteúdo e forma: a coincidência entre o universal e o particular, a autodeterminação do povo como "muitos unos". Assim, a democracia realizada implicaria a abolição do Estado e, consequentemente, da sociedade civil. A condição para o desaparecimento do Estado seria o fim da propriedade privada (que é o verdadeiro sentido do Estado, que começa com a "expropriação original"). O que liga o universal e o particular é, claro, o proletariado, "classe universal, uma massa situada virtualmente além da condição de classe, cuja particularidade já seria negada em suas condições de existência" (BALIBAR apud TIBLE, 2020, p. 130).

Segundo Tible, Marx passa cada vez mais a ver o Estado como parasita, sendo a sua ação apenas a de reprimir. Ao mesmo tempo, não há capitalismo sem Estado: ele é o principal agente na criação do trabalho livre e do mercado, e é pela sua violência que se regulam os salários. Marx teria ligado isso à violência colonial, a "acumulação original" que permite o funcionamento da máquina. Tible evoca a leitura politizante de Marx por Chatelet, que vê como condicionante a operação violenta da "acumulação original". A ideia de que há uma violência política originária que permite a passagem para a consideração das ideias de Pierre Clastres, que rejeitou enfaticamente o evolucionismo ou a teleologia presente em parte da antropologia de inspiração marxista. Tible explica um tanto superficialmente o que seriam os três pontos da tese clastreana do "contra o Estado": a chefia, a guerra e os mitos/ parentesco. A leitura de Tible se aproxima mais das abordagens que privilegiam em Clastres a determinação de uma intencionalidade coletiva 
que controla e limita o poder do chefe indigena.

Depois de voltar brevemente a Marx para expor as controvérsias entre Marx e Bakunin e entre Marx e Lassalle, Tible chega ao que talvez seja o ponto mais interessante neste capítulo: a exposição da leitura clastreana de Marx feita por Deleuze e Guattari. Essa leitura indica que o capitalismo, ao pressupor a acumulação originária, constitui-se como aparelho de captura. Isto é, a violência política é anterior, e a diferença entre as "sociedades contra o Estado" e as sociedades de classes está na política, e não em niveis de desenvolvimento ou de progresso das forças produtivas. Essa ideia pode ser resumida em uma frase de Deleuze e Guattari: "não é o Estado que supõe um modo de produção, mas o inverso, é o Estado que faz da produção um modo" (apud TIBLE, 2020, p. 203). Tible encerra o capítulo procurando mostrar que Marx pensa sempre em um engajamento com "as lutas", assim como Clastres (com "as lutas ameríndias"), e é isto que os coloca juntos em uma oposição ao "Um do Estado": "o terreno comum do encontro entre Marx e América Indígena é o das lutas" (2020, p. 222).

O terceiro capítulo é o mais aproximativo, no qual o autor navega com menos segurança. Nele, Tible expõe, de uma maneira um pouco confusa alguns temas que têm se tornado notórios na literatura etnológica brasileira, tentando, ao final, mostrar como "as lutas amerindias" interpelam Marx (2020, p. 227). Ele começa retomando a valorização marxiana da organização da comuna de Paris, para tirar daí uma imagem de "associação" que seria aproximada àquela da Liga dos Iroqueses descrita por Morgan; bem como daquilo que ele chama de uma "democracia conselhista", que teria emergido no debate sobre a autonomia dos territórios indigenas frente ao Estado do Amazonas na Venezuela (baseando-se no relato de Catherine Alés). Marx e os Yanomami se aproximariam por um apreço comum à "forma-conselho - práticas contra o Estado" (2020, p. 237). Para essa formulação, cujas bases etnográficas são bastante frágeis, Tible se apoia nas palavras-chave da filosofia de Tony Negri ("positividade das lutas", "processos constituintes" etc.).
Depois de aproximar de uma versão resumida das intervenções de Davi Kopenawa e Bruce Albert e, então, do "perspectivismo ameríndio", tal como formulado por Eduardo Viveiros de Castro, Tible extrai dos textos de Viveiros de Castro algumas críticas à Marx, resumidas na oposição entre produção e predação, e na questão do antropocentrismo onipresente na obra marxiana, em especial nos Manuscritos Econômico Filosóficos. A crítica perspectivista ao paradigma sociológico da produção, que nos textos de Viveiros de Castro aparece relacionada à reavaliação do papel desempenhado pela ideia africanista de "filiação" na obra conjunta de Deleuze e Guattari, é de certa maneira confusamente achatada (2020, p. 258). De qualquer forma, Tible pretende defender Marx dessas críticas, enfatizando especialmente o tema da unidade do homem e da natureza na produção, presente na obra do jovem Marx (2020, p. 267). Mais do que resolvida, a questão é eludida com o auxílio de uma formulação de Isabelle Stengers e Philippe Pignarre: "o ponto crucial não é então de se colocar de acordo sobre o que Marx escreveu".

Na última parte do capítulo, Tible segue a pista dada por Bruce Albert, que aproximou as intervenções críticas de Davi Kopenawa à análise de Marx sobre o fetichismo da mercadoria. No entanto, apesar de querer conferir uma profundidade analítica maior a essa aproximação, Tible parece se contentar com uma justaposição simples da interpretação marxiana do fetichismo da mercadoria, das críticas de Kopenawa ao "povo da mercadoria", da ideia de "feitiçaria capitalista" da Stengers e do Pignarre, e das conhecidas observações antropológicas sobre o contraste entre a mercadoria e o dom. Seria preciso observar, por exemplo, que o movimento crítico de Marx vai em sentido contrário ao uso da ideia de "feitiçaria" por Stengers e Pignarre: nesses autores não se trata propriamente de "desfazer ilusões" ou desvelar processos ignorados pelos trabalhadores. O capítulo é encerrado com observações acerca de uma "ontologia relacionalista" que Marx compartilharia com os ameríndios, e do "caráter cosmopolítico e constituinte da produção". 
Na conclusão do livro, Tible afirma que o encontro entre Marx e os Amerindios é um caso da "construção de um mundo plural, mas comum" (e aqui ele se refere ao título de uma entrevista concedida por Bruno Latour, em 2003). Novamente, as formulações generalistas de Antônio Negri auxiliam o autor a aproximar Marx da etnologia amazônica: "se o comum implica, assim, um diálogo entre mundos, sua articulação só é possivel pelas conexões das lutas" (2020, p. 295). Essa aproximação baseia-se na elaboração de um "Marx entre" (ou de um "Marx marrano", como dizia Derrida). O livro encerra-se com uma breve referência à filosofia de Oswald de Andrade, evocando-o como inspirador dessa imagem de um "Marx selvagem".

O livro apresenta, entre outros méritos, o valor de levantar com clareza duas questões que interessam àqueles que se perguntam pelas possiveis ligações entre as lutas de descolonização latino-americanas, a situação dos povos indígenas e amazônicos, e as perspectivas postas para o pensamento de esquerda na América do Sul. A primeira, diz respeito à possibilidade de conceitualização dos enfrentamentos coloniais e pós-coLoniais na América do Sul segundo o fraseado de Antonio Negri e Michael Hardt. Jean Tible sugere, assim, que a resiliência indigena, provocada pela natureza "contra o Estado" ou "para a guerra" de suas sociedades, poderia ser pensada juntamente com as "lutas" pela emancipação dos movimentos sociais no Ocidente. Para além da aproximação conceitual vaga, essa é uma questão principalmente pragmática, e seria mais importante observar como esses encontros têm se dado de fato.

A segunda questão toca as formulações marxistas sobre a "subsunção formal" e a "subsunção real": os coletivos indigenas nas terras baixas sul-americanas podem ser pensados como apresentando formas societárias que estão "fora" do capitalismo? Tible parece optar por pensar a questão como Negri e Hardt: não há "fora" do capitalismo, e seria justamente ao se verem atacados pelos modos da expropriação modalizados pela acumulação original que os indios se tornam acessiveis ao pensamento do "comum". Tenho a impressão que Tible, ao pensar com
Marx que o Estado é condição de possibilidade do capitalismo (pela criação do trabalho livre e pela comensuração dos valores através da moeda), acaba fazendo equivaler as duas dimensões, que são tratadas em separado por Deleuze e Guattari, por exemplo. A emergência do Estado é condição para a instituição do capitalismo, mas trata-se de coisas diferentes (já que, para falar com Deleuze e Guattari, o próprio capitalismo, com sua decodificação generalizada dos fluxos, atenta o tempo todo contra as estruturas paranoicas do Estado).

Sobre as sociedades contra o Estado, Deleuze e Guattari admitem que elas constituem um "fora do Estado", mas não uma exterioridade pura (que seria antes a "máquina de guerra nômade", conceito derivado mas não equivalente à "sociedade primitiva" de Clastres): trata-se dos mecanismos de antecipação e conjuração (em referência a Clastres) dos aparelhos de captura da soberania - i.e., a renda (captura e estriação de territórios), o lucro (a criação do trabalho livre e a sua alienação), e o imposto (padronização dos valores de troca e o controle da moeda). É apenas do ponto de vista desses aparelhos de captura (i.e., do ponto de vista estatal) que a questão se torna "dentro ou fora": "o Estado mesmo esteve sempre em relação com um fora e não é pensável de modo independente dessa relação. A lei do Estado não é a do Tudo ou Nada, mas a do interior e do exterior" (como escrevem Deleuze e Guattari em uma passagem citada pelo próprio Tible - 2020, p. 217-218).

Se pretendemos colocar essa questão (assumindo o ponto de vista a partir do qual ela faz sentido, i.e., de um pensamento "para o Estado", e mantendo a sobreposição de Tible entre capitalismo e Estado), seria forçoso concluir que os indios estão "fora", justamente porque suas formas de socialidade se adequam muito pouco às formas capitalistas ou estatais de conformação da produção: no geral (e a abstração para além de qualquer solo etnográfico especifico é resultado do "ponto de vista estatal" adotado pela questão), não há nada nas relações intracomunitárias que se assemelhe aos princípios de comensuração 
pressupostos pela criação do trabalho livre, ou de valores de troca, por exemplo. No entanto, é preciso notar, esse "estar fora" supõe uma configuração pouco intuitiva: trata-se de um "fora" que está, de algum modo, "dentro", uma vez que Estado e capitalismo são sistemas dentre outros sistemas exteriores que as comunidades indigenas internalizam em operações predatórias arriscadas. Essas sociedades indígenas nunca estiveram isoladas, pois o seu interior sempre foi moldado a partir da predação de condições exteriores. Como os mitos ameríndios, as sociedades indigenas tendem a assumir a forma de garrafas de Klein (para falar como Lévi-Strauss). Ou, em um exemplo concreto, basta lembrarmo-nos dos Tzeltal de chiapas, no México, para os quais cada indígena tem, dentro de si, envolvidas por um corpo materialmente produzido como indigena (i.e., como corpo de parente), um punhado de almas "castilhanas".

Na verdade, a melhor resposta à ânsia dos negrianos por colocar as sociedades indigenas em um "comum das lutas" me parece ter sido dada por Isabelle Stengers:

Se o capitalismo precisa, depende e propaga a vulnerabilidade aos seus "ataques", dever-se-ia acolher a famosa tese marxista de que ele está assim abrindo caminho para o socialismo, através de seu próprio processo de destruição de formas de vida "tradicionais" (que, portanto, não vale a pena defender). E também dever-se-ia acolher a versão revolucionária do refrão moderno da "grande divisão": de uma forma ou de outra, a luta contra o capitalismo seria considerada como a final - uma batalha apocalíptica entre luz e escuridão - numa paisagem brutalmente purificada dos grilhões do passado. $\mathrm{Na}$ verdade, isso significa que aqueles que lutam têm de manter os olhos fixos em um embate final, que eles devem fechar os ouvidos contra os gritos e o desespero daqueles cujas culturas, práticas e apegos foram destruidos. E que eles devem dar uma importância sem precedentes à "teoria" como o guia necessário, a bússola indispensável diante de todas as tentações e desvios. Da definição de Marx, do proletariado como tendo nada mais que cadeias a perder, à definição de Negri da "multidão", a teoria aparece então como um "teatro dos conceitos", identificando-se como o exemplo conceptual puro capaz de erigir um padrão digno em um confronto que é também o de gerar uma Humanidade finalmente reconciliada. Tal teatro, no entanto, não oferece o que as tradições não-modernas, que sabem sobre feitiçaria, sabem cultivar: artes de proteção contra a captura (STENGERS, 2008, p. 56).
Independentemente da posição que tomemos nesse debate, o livro de Jean Tible se coloca claramente como parte das tentativas recentes de limpar a obra Marx de seu espírito "desenvolvimentista" e de seu antropocentrismo e universalismo oitocentista, aproximando-o do perspectivismo ameríndio. Seria isso ainda um suspiro do mundialismo ou do internacionalismo marxista? Por fim, caberia perguntar, afinal, se valeria mesmo a pena o esforço de tentar fazer Marx e os ameríndios (mas, afinal, quais amerindios? os Yanomami? ou Davi Kopenawa? ou os Aché-Guayaki com os quais Clastres estudou?) dizerem mais ou menos as mesmas coisas, no lugar de querer colocá-los em relação enquanto diferentes perspectivas. Marx-irmão ou Marx-cunhado? Marx selvagem?

\section{Referências}

STENGERS, Isabelle. Experimenting with refrains. Subjectivity 22, p. 38-59, 2008. https://doi.org/10.1057/ sub.2008.6

TIBLE, Jean. Marx Selvagem. 4. ed. São Paulo: Autonomia Literária, 2020

\section{Marcos de Almeida Matos}

Doutor em Antropologia Social pela Universidade Federal de Santa Catarina (UFSC), em Florianópolis, SC, Brasil; professor adjunto da Universidade Federal do Acre (UFAC), em Rio Branco, AC, Brasil.

\section{Endereço para correspondência}

Marcos de Almeida Matos,

Universidade Federal do Acre, Centro de Filosofia e Ciências Humanas

Rodovia BR 364, Km 04

Distrito Industrial, 69920900

Rio Branco, AC, Brasil 